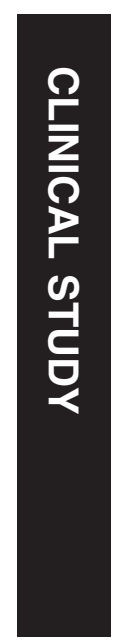

\title{
Ocular residual astigmatism's effect on high myopic astigmatism LASIK surgery
}

${ }^{1}$ Department of

Ophthalmology, Príncipe de Asturias University Hospital, University of Alcalá, Madrid Spain

${ }^{2}$ Novovision Madrid Madrid, Spain

${ }^{3} 1$ st University Department of Ophthalmology, Aristotle University of Thessaloniki, Thessaloniki, Greece

Correspondence:

C Arruabarrena,

Oftalmología, Hospital

Universitario Principe de

Asturias, Ctra. Meco,

Alcalá de Henares, 28805

Madrid, Spain

Tel: +34918878100

ext 2189;

Fax: +34 918878100

E-mail: carruabarrenas@

gmail.com

Received: 13 January 2014 Accepted in revised form:

27 April 2014

Published online:

27 June 2014

The results of this article were presented in part in the XXX Congress of the ESCRS in Milano (Italy), September 2012.

\begin{abstract}
Purpose To analyze the effect of ocular residual astigmatism (ORA) on the effectiveness of LASIK for treating high myopic astigmatism.

Methods This is an observational, crosssectional study. We studied 116 consecutive myopic eyes with -3 diopters (D) or more of astigmatism that underwent LASIK surgery.

The magnitude of uncorrected residual refractive astigmatism 3 months postoperatively was measured.

Results The mean preoperative cylinder was $-4.0 \pm 0.83 \mathrm{D}$ (range, -7.5 to $-3 \mathrm{D}$ ) and the mean preoperative ORA was $0.82 \pm 0.5 \mathrm{D}$. The mean residual refractive cylinder 3 months postoperatively was $-0.78 \pm 0.83 \mathrm{D}$ (range, -3 to 0 D). No correlation was found between ORA and the refractive cylinder 3 months postoperatively $(P=0.6)$.

Conclusion In eyes with high myopic astigmatism undergoing LASIK, ORA was not correlated with the residual postoperative cylinder.

Eye (2014) 28, 1014-1019; doi:10.1038/eye.2014.133; published online 27 June 2014
\end{abstract}

\section{Introduction}

Ninety percent of the world's population have some extent of ocular astigmatism, and up to $20 \%$ have astigmatism of $\geq 1.5$ diopters (D). ${ }^{1,2}$

Several techniques have been developed to surgically correct astigmatic errors, including transverse or arcuate incisions (simple, combined, or in conjunction with radial incisions). Excimer laser corneal refractive surgery is safe and efficient for correcting astigmatism in adults. ${ }^{3-6}$ However, LASIK might be less effective for correcting
MA Teus ${ }^{1,2}$, C Arruabarrena 1,2 JL Hernández-Verdejo ${ }^{2}$, R Cañones ${ }^{1}$ and DG Mikropoulos ${ }^{3}$ astigmatism than for correcting sphere, and even less effective when treating eyes with high intraocular astigmatism. ${ }^{7-12}$

LASIK correction of refractive astigmatism is performed by reshaping the anterior corneal surface. Nevertheless, refractive astigmatism is the sum of anterior corneal astigmatism (ACA) and intraocular astigmatism, which seems to be induced mainly by the posterior corneal surface and the lens. ${ }^{13}$ Vector analysis methods can be used to quantify intraocular astigmatism, commonly referred as ocular residual astigmatism (ORA), both in magnitude and in axis.

It is widely accepted that refractive astigmatism results mainly from ACA, and that ORA is usually of low magnitude. Alpins ${ }^{7}$ initially evaluated 100 patients and reported a mean ORA value of $0.81 \mathrm{D}$; in a second study ${ }^{14}$ he reported a mean of $0.73 \mathrm{D}$. Srivannaboon ${ }^{15}$ reported ORA values $>1.00 \mathrm{D}$ in one-third of 220 study eyes. However, these studies were performed in eyes with $<3.5 \mathrm{D}$ of refractive astigmatism, so there are no good-quality data currently available on the magnitude of ORA in eyes with high refractive astigmatism (eyes with $\geq-3$ diopters (D) of astigmatism).

Renewed interest is being expressed in ORA, because recent studies ${ }^{16,17}$ suggest that LASIK correction of low myopic refractive astigmatism has a better refractive outcome if the preoperative refractive astigmatism arises primarily from the anterior corneal surface. In these eyes, keratometric, topographic, and refractive astigmatism are similar to each other in magnitude and axis. In contrast, the same authors ${ }^{16}$ have reported that the efficacy of LASIK to correct low myopic astigmatism was significantly lower in eyes with high preoperative ORA (defined as ORA/R $\geq 1, R$ being the preoperative refractive astigmatism). A possible explanation for this might be that in 
eyes with high ORA LASIK must create a toric cornea to compensate for ORA, which can affect the postoperative visual results. ${ }^{9-11}$

The lack of data on the magnitude of ORA in eyes with high myopic astigmatism and its possible effect on the efficacy of LASIK prompted us to analyze the effect of ORA on LASIK performed to correct high myopic astigmatism.

\section{Materials and methods}

This was a retrospective observational study that included 116 eyes of consecutive patients who fulfilled the inclusion criteria. The inclusion criteria were that patients had to be older than 18 years (range, 20-57), candidates for LASIK, and have a refractive astigmatism of at least $-3 \mathrm{D}$ or more. When both eyes of the same patient fulfilled the inclusion criteria, only the right eye was included. So only one eye per patient was analyzed.

The exclusion criteria included a history of glaucoma or retinal detachment, corneal disease, a previous corneal or intraocular surgery, an abnormal iris, pupil deformation, macular degeneration or retinopathy, the presence of neuro-ophthalmic diseases, surgical complications or postoperative macular edema, and a history of ocular inflammation.

This research was conducted according to the tenets of the Declaration of Helsinki. All subjects provided informed consent before participation in the study. The institutional review board of our centre approved the study protocol.

The same experienced surgeon (MAT) performed all LASIK procedures using the Moria 2 microkeratome (Moria, Anthony, France). The ablation was performed with an Esiris excimer laser (Schwind, Kleinostheim, Germany) in all cases. The postoperative follow-up included visits at 1 day, and 1, 4, and 12 weeks in all cases.

At the baseline preoperative visit, an optometrist and the surgeon performed a complete ocular examination, which included measurement of the manifest refraction and visual acuity (VA) (Auto Chart projector, Nidek, CP-670, Gamagori, Japan), keratometry (autokeratorefractometer, Topcon KR-800, Tokyo, Japan), slit-lamp biomicroscopy, Goldmann applanation tonometry, corneal topography (CSO, Compagnia Strumenti Oftalmici, Florence, Italy), and binocular indirect ophthalmoscopy through a dilated pupil. The same examiners performed the same complete ocular examination at the 3-month postoperative visit.

VA was measured with Snellen optotypes, and values are expressed in decimal notation, but they were converted to the LogMAR notation for statistical analysis. Astigmatism is always expressed as a negative value.

\section{Astigmatism analysis}

Keratometric and objective refractive measurements were obtained using an autokeratorefractometer. The subjective refraction was evaluated using a phoropter at a nominal vertex distance of $13.75 \mathrm{~mm}$ with the corneal vertex located at the large mark on the calibration scale. ${ }^{18}$ Refractive postoperative astigmatic values were converted to the power vector components using the method described by Thibos and Horner. ${ }^{19}$ Thus, refractions are considered to be the sum of the spherical equivalent; that is, a Jackson cross-cylinder oriented at $180^{\circ}$ (referred to as J0) quantified with-the-rule and against-the-rule astigmatism, and a Jackson crosscylinder oriented at $45^{\circ}$ (referred to as J45) quantified oblique astigmatism. In this way, we expressed any spherocylindrical refractive error in three dioptric powers (M, J0, J45), shown graphically as the three $(x, y, z)$ coordinates of a point in a three-dimensional dioptric space. The length of this vector was a measure of the overall blurring strength of any spherocylindrical lens or refractive error. The conventional notation of the refractive and keratometric astigmatism values was converted to power vector coordinates using the following formulas:

$\mathrm{J} 0=(\mathrm{C} / 2) \times \cos (2 \mathrm{alpha})$

$\mathrm{J} 45=(-C / 2) \times \sin (2 \mathrm{alpha})$

where $C$ is the astigmatism power, and alpha is the angle of the astigmatism.

The difference vector was then computed by subtracting the corresponding values along each of the coordinate axes separately.

The following vectors were determined and evaluated: ORA, which is the vector value arising from any nonanterior corneal source, and is the vector difference between the preoperative refractive astigmatism at the corneal plane and keratometric astigmatism; the target intended astigmatism (TIA), which is the vector of the intended change in the cylinder for each treatment, and is equivalent to the preoperative refractive astigmatism; and the surgically induced astigmatism (SIA), which is the vector difference between the postoperative refractive astigmatism and the preoperative refractive astigmatism - in other words, it is the actual astigmatic change achieved.

The patient sample was divided into two groups based on the amount of ORA. Patients with an ORA exceeding the mean were considered the high ORA group (44 eyes), 
and patients with an ORA equal to or lower than the mean were considered the low ORA group (71 eyes).

\section{Statistical analysis}

The relationships between either the preoperative cylinder or the ORA, and the improvement in the best spectacle-corrected visual acuity (BSCVA), spherical error, and residual cylinder were assessed using linear regression analysis and Pearson's correlation coefficient. For other comparisons, the unpaired, two-tailed Student's $t$-test was used. $P$-values $<0.05$ were considered significant.

The data were analyzed using StatView SE + Graphics (Abacus Concepts Inc., Berkeley, CA, USA) and a personal computer Macintosh PowerBook 1400cs/117 (Apple Computer Inc., Cupertino, CA, USA).

\section{Results}

A total of 116 eyes with a high myopic astigmatic refractive error treated with LASIK were included. The mean patient age was $35.63 \pm 7.75$ years (range, 20-57). The mean optical zone was $5.99 \pm 0.43 \mathrm{~mm}$ (range, 5.0 to 7.5). Table 1 shows the refractive and keratometric characteristics and the BSCVA preoperatively and 3 months postoperatively.

The preoperative refractive cylinder was not correlated with the patient's age $(P=0.8)$. The preoperative refractive cylinder was significantly correlated with the 3 -month post-op sphere and astigmatism $\left(R^{2}=0.04\right.$, $P=0.01$ and $R^{2}=0.18, P=0.001$, respectively). In other words, the greater the preoperative cylinder, the greater the residual cylinder 3 months after LASIK.

The mean preoperative ORA was $0.82 \pm 0.5 \mathrm{D}$ (range, 0.09 to $2.29 \mathrm{D})$. We found no significant correlation between the preoperative ORA and the preoperative refractive cylinder $(P=0.3)$, the postoperative cylinder $(P=0.6)$, or the change in the BSCVA 3 months after surgery $(P=0.6)$. A weak but significant correlation was found between the preoperative ORA and the postoperative residual sphere at 3 months $\left(R^{2}=0.04\right.$, $P=0.01)$.

Table 2 shows the vector analysis of ORA, TIA, and SIA.

When we divided the original sample into two groups based on the ORA magnitude (those with an ORA higher or lower than the mean, ie, $0.82 \mathrm{D}$ ), we found that the mean ORA in the high ORA group (44 eyes) was $1.54 \pm 0.78 \mathrm{D}$ and the that in the low ORA group (71 eyes) was $0.54 \pm 0.21 \mathrm{D}$. There were no significant differences in the preoperative cylinder, residual cylinder, or the increase in the logMAR BSCVA between both groups (Table 3).

As no difference was found between the two groups we calculated the number of cases per group needed to have a power of $90 \%$ (with an alpha error $=0.05$ ) to detect a difference of at least $0.5 \mathrm{D}$ (considering that the standard deviation of the residual astigmatism after LASIK is $0.46 \mathrm{D}^{20}$ ). The number of eyes needed is 22 per group. Given the fact that the number of eyes in the high ORA group was 44, and in the low ORA group was 71, then we would have been able to detect differences in the astigmatism correction between groups of $<0.5 \mathrm{D}$.

Table 1 Refractive and keratometric characteristics and the BSCVA preoperatively and 3 months postoperatively

\begin{tabular}{lcc}
\hline & Preoperatively, mean \pm SD (range) & 3 Months postoperatively, mean \pm SD (range) \\
\hline Sphere & $-3.89 \pm 2.61 \mathrm{D}(0$ to 11.5$)$ & $0.03 \pm 0.59(-1.5$ to 1.75$)$ \\
Refractive cylinder & $-4.00 \pm 0.83 \mathrm{D}(-7.5$ to -3$)$ & $-0.78 \pm 0.83(-3$ to 0$)$ \\
J0 & $1.20 \pm 0.89(-1.66$ to 3.38$)$ & $0.19 \pm 0.38(-1.09$ to 1.39$)$ \\
J45 & $0.05 \pm 0.88(-1.77$ to 2.21$)$ & $0.01 \pm 0.028(-0.95$ to 0.75$)$ \\
K1 & $42.26 \pm 1.45(39.5$ to 46$)$ & $38.75 \pm 2.22(32.75$ to 43.25$)$ \\
K2 & $45.30 \pm 1.55(41.75$ to 48.75$)$ & $40.29 \pm 2.13(34.75$ to 45.5$)$ \\
BSCVA logMAR & $0.11 \pm 0.11(0.02$ to 0.8$)$ & $0.08 \pm 0.11(-0.1$ to 0.86$)$ \\
BSCVA decimal notation & $0.79 \pm 0.16(0.15$ to 0.95$)$ & $0.84 \pm 0.17(0.15$ to 1.25$)$ \\
\hline
\end{tabular}

Abbreviations: BSCVA logMAR, best spectacle-corrected visual acuity logarithm of the mínimum angle of resolution; D, diopters.

Table 2 Vector analysis

\begin{tabular}{lccr}
\hline & ORA, mean $\pm S D$ (range) & TIA, mean $\pm S D$ (range) & SIA, mean $\pm S D$ (range) \\
\hline J0 & $0.05 \pm 0.31(-1.13$ to 0.47$)$ & $1.27 \pm 0.89(-1.66$ to 3.38$)$ & $1.01 \pm 0.87(-1.66$ to 4.47$)$ \\
J45 & $0.08 \pm 0.35(-1.12$ to 0.98$)$ & $0.11 \pm 0.88(-1.77$ to 2.21$)$ & $0.08 \pm 0.81(-1.72$ to 1.82$)$ \\
\hline
\end{tabular}

Abbreviations: ORA, ocular residual astigmatism; SIA, surgically induced astigmatism; TIA, target intended astigmatism.

All data are expressed in diopters. 
Table 3 Results by group: high ORA and low ORA

\begin{tabular}{lccc}
\hline & High ORA group & Low ORA group & P-value \\
$\mathrm{N}=44$ & $($ mean \pm SD) & $($ mean \pm SD) & $\begin{array}{c}\text { (unpaired Student } \mathrm{t} \text {-test) } \\
\text { Preoperative cylinder }\end{array}$ \\
Postoperative cylinder at 3 months & $-4.13 \pm 0.88$ & $-3.92 \pm 0.80$ & 0.1 \\
BSCVA preoperative-postoperative logMAR & $-0.72 \pm 0.87$ & $-0.81 \pm 0.81$ & 0.5 \\
\hline
\end{tabular}

Abbreviations: BSCVA, best spectacle-corrected visual acuity; logMAR, logarithm of the minimum angle of resolution; ORA, ocular residual astigmatism.

Regarding the astigmatic axis, we found a mean difference in the values between the axes of the keratometric and refractive astigmatism of $4.24 \pm 3.36^{\circ}$ (range, $0-15^{\circ}$ ). There was no significant correlation between the difference in the axes of the keratometric and refractive preoperative astigmatism and the residual refractive astigmatism 3 months postoperatively $(P=0.7)$, the efficacy index $(P=0.7)$, the safety index $(P=0.23)$ of the procedure, the BSCVA 3 months postoperatively $(P=0.47)$, or the improvement in the BSCVA 3 months postoperatively $(P=0.3)$. We found a weak but significant correlation between the preoperative ORA and the difference between the keratometric and the refractive astigmatism axes $\left(R^{2}=0.25 ; P=0.001\right)$. Eyes with a greater difference between the keratometric and the refractive astigmatism axes had higher ORA values.

\section{Conclusion}

We found that the magnitude of ORA does not seem to affect the refractive results obtained after performing LASIK to correct high myopic astigmatism.

The refractive astigmatism is a refractive error derived from several ocular structures: the anterior corneal surface toricity and the toric optical power of the nonanterior corneal elements located inside the eye (the ORA). In eyes with high ORA, a discrepancy between the keratometric astigmatism and the refractive astigmatism is found. ${ }^{7,9-11}$ Thus, the ORA represents the sum of all the intraocular astigmatism, including the astigmatism from the posterior corneal surface, lens, vitreous, and retina. ${ }^{21}$ While it is commonly accepted that the main source of ORA is the lens, it has been shown that even pseudophakic eyes have ORA. ${ }^{13}$

Alpins's initial study of 100 normal patients ${ }^{7}$ reported a mean ORA value of $0.81 \mathrm{D}$; in $34 \%$ of the eyes the ORA exceeded 1.00 D. In a second study, ${ }^{14}$ he found a mean ORA value of 0.73 D. Later, Srivannaboon ${ }^{15}$ found ORA values $>1.00 \mathrm{D}$ in a third of the eyes analysed. In the current study, in which we analyzed only eyes with high myopic astigmatism, we found a mean ORA value close to $0.8 \mathrm{D}(0.82 \pm 0.5 \mathrm{D}$; range, 0.09-2.29 D), quite similar to the magnitude of ORA reported for the normal population. ${ }^{14,15}$ Thus, it seems that the magnitude of the ORA is quite independent of the magnitude of the refractive astigmatism.

LASIK is an efficient and safe procedure for correcting myopia, hypermetropia, and astigmatism. ${ }^{22}$ The efficacy of LASIK is well established; however, it seems to be less effective for correcting astigmatism than for correcting spherical refractive errors, and some studies have reported that the presence of preoperative astigmatism increases the retreatment rate after surgery. ${ }^{23,24}$

Some studies have suggested that the refractive results after performing LASIK in eyes with low myopic astigmatism seem to be worse in those eyes that have a significant amount of preoperative ORA, ${ }^{16,17}$ even suggesting that when significant ORA is identified preoperatively, it might be prudent to incorporate a vector planning into the surgical plan.

The current study is the first, to the best of our knowledge, to evaluate the effect of preoperative ORA on the efficacy of LASIK performed in patients with high myopic astigmatism. We found that preoperative ORA did not affect the surgical efficacy, because ORA was not correlated with the residual refractive cylinder or with the improvement in the BSCVA 3 months postoperatively. Even when we analyzed a subgroup of eyes with high preoperative ORA, we did not find a significant correlation between the ORA and either the residual cylinder or the BSCVA change 3 months postoperatively.

We, unexpectedly, found that the ORA was correlated significantly with the residual sphere 3 months after LASIK, but the correlation coefficient was low and probably not clinically relevant.

Regarding the astigmatic axis, we found that the difference in axes between the corneal and the refractive astigmatism was low, ranging from $0^{\circ}$ to $15^{\circ}$. This difference tended to be greater in eyes with higher ORA levels $\left(R^{2}=0.25 ; P=0.001\right)$. In addition, the difference in the axes between refractive and keratometric astigmatism did not seem to affect the residual astigmatism or the changes in BSCVA after LASIK.

On the basis of our findings, we believe that in eyes with high myopic astigmatism the ORA seems to be 
independent of the magnitude of the refractive astigmatism and that it is similar to the values found in the general population. This suggests that the primary source of astigmatism in eyes with high myopic astigmatism is mainly the anterior corneal surface.

We also found that the visual and refractive results obtained after performing LASIK to correct high myopic astigmatism did not seem to be affected by the magnitude of the preoperative ORA. This seems to contradict the findings of Kugler et al ${ }^{16}$ and Qian et al, ${ }^{17}$ who studied the effectiveness of LASIK for correcting low myopic astigmatism and found significantly better refractive results in eyes with low ORA than in eyes with high ORA.

We can only speculate about the reasons for the different effects of ORA on the efficacy of LASIK in eyes with either high or low refractive myopic astigmatism. It makes sense that, given the fact that the magnitude of the ORA seems to be similar in eyes with high myopic astigmatism than in those with low myopic astigmatism, then the ORA/ACA ratio would be higher in the latter group. This fact could explain why the preoperative ORA seems to play a significant role in the refractive outcome of eyes with low preoperative refractive astigmatism, ${ }^{16,17}$ but seems to have a negligible effect in eyes with high preoperative astigmatism (as we found in the current paper).

We suggest that rather than the effect of preoperative ORA, it is the ORA/ACA ratio that seems to be relevant for the refractive correction, and this ratio explains better the findings of both the current paper, and those of Kugler et $a l^{16}$ and Qian et al ${ }^{17}$ than the preoperative ORA.

It is evident that the correction of astigmatism is a complex issue, and that further studies should be conducted to increase our understanding of the factors affecting the results obtained after performing LASIK to correct myopic astigmatism.

\section{What was known before}

- It has been reported that the efficacy of LASIK to correct low myopic astigmatism was significantly lower in eyes with high preoperative ORA.

What this study adds

- This study adds data on the magnitude of ORA in eyes with high myopic astigmatism and its possible effect on the efficacy of LASIK, and prompted us to analyze the effect of ORA on LASIK performed to correct high myopic astigmatism.

\section{Conflict of interest}

The authors declare no conflict of interest.

\section{References}

1 Hoffer KJ. Biometry of 7500 cataractous eyes. Am J Ophthalmol 1980; 90: 360-368; (correction, 890).

2 Ferrer-Blasco T, Montes-Micó R, Peixoto-de Matos S, González-Meíjome JM, Cerviño A. Prevalence of corneal astigmatism before cataract surgery. J Cataract Refract Surg 2009; 35: 70-75.

3 Handzel A, Kenikstul N, Handzel T. Laser in situ keratomileusis for astigmatism greater than $-3.50 \mathrm{D}$ with the Nidek EC-5000 excimer laser. J Refract Surg 2003; 19(Suppl 2): S241-S242.

4 Shaikh N, Manche E. Laser in situ keratomileusis for myopia and compound myopic astigmatism using the Technolas 217 scanning-spot laser. J Cataract Refract Surg 2002; 28: 485-490.

5 Albarrán-Diego C, Muñoz G, Montés-Micó R, Alió JL. Bitoric laser in situ keratomileusis for astigmatism. J Cataract Refract Surg 2004; 30: 1471-1478.

6 Lui MM, Silas MA, Apelbaum B, Oshima A. Laser in situ keratomileusis with the Nidek EC-5000 excimer laser for astigmatism greater than 4.00 D. J Refract Surg 2002; 18: S321-S322.

7 Alpins NA. New method of targeting vectors to treat astigmatism. J Cataract Refract Surg 1997; 23: 65-75.

8 Alpins N. Astigmatism analysis by the Alpins method. J Cataract Refract Surg 2001; 27: 31-49.

9 Artal P, Guirao A, Berrio E, Williams DR. Compensation of corneal aberrations by the internal optics in the human eye. J Vis 2001; 1: 1-8.

10 Atchison DA. Anterior corneal and internal contributions to peripheral aberrations of human eyes. J Opt Soc Am A Opt Image Sci Vis 2004; 21: 355-359.

11 Mrochen M, Jankov M, Bueeler M, Seiler T. Correlation between corneal and total wavefront aberrations in myopic eyes. J Refract Surg 2003; 19: 104-112.

12 Bragheeth MA, Dua HS. Effect of refractive and topographic astigmatic axis on LASIK correction of myopic astigmatism. J Refract Surg 2005; 21: 269-275.

13 Teus MA, Arruabarrena C, Hernández-Verdejo JL, Sales-Sanz A, Sales-Sanz M. Correlation between keratometric and refractive astigmatism in pseudophakic eyes. J Cataract Refract Surg 2010; 36: 1671-1675.

14 Alpins NA. A new method of analyzing vectors for changes in astigmatism. J Cataract Refract Surg 1993; 19: 524-533.

15 Srivannaboon S. Internal astigmatism and its correlation to corneal and refractive astigmatism. J Med Assoc Thai 2003; 86: 166-171.

16 Kugler L, Cohen I, Haddad W, Wang MX. Efficacy of laser in situ keratomileusis in correcting anterior and nonanterior corneal astigmatism: Comparative study. J Cataract Refract Surg 2010; 36: 1745-1752.

17 Qian YS, Huang J, Liu R et al. Influence of internal optical astigmatism on the correction of myopic astigmatism by LASIK. J Refract Surg 2011; 27(12): 863-868.

18 Holladay JT, Moran JR, Kerizian M. Analysis of aggregate surgically induced refractive changes, prediction error, and intraocular astigmatism. J Cataract Refract Surg 2001; 27: 61-79.

19 Thibos LN, Horner D. Power vector analysis of the optical outcome of refractive surgery. J Cataract Refract Surg 2001; 27: $80-85$

20 Schallhorn SC, Venter JA. One-month outcomes of wavefront-guided LASIK for low to moderate myopia with the VISX STAR S4 laser in 32,569 eyes. J Refract Surg 2009; 25(7 Suppl): S634-S641. 
21 Alpins NA. Treatment of irregular astigmatism. J Cataract Refract Surg 1998; 24: 634-646.

22 Sugar A, Rapuano CJ, Culbertson WW, Huang D, Varley GA, Agapitos PJ et al. Laser in situ keratomileusis for myopia and astigmatism: safety and efficacy: a report by the American Academy of Ophthalmology. Ophthalmology 2002; 109: 175-187.
23 Hersh PS, Fry KL, Bishop DS. Incidence and associations of retreatment after LASIK. Ophthalmology 2003; 110: 748-754.

24 Randleman JB, White AJ, Lynn MJ, Hu MH, Stulting RD. Incidence, outcomes, and risk factors for retreatment after wavefront-optimized ablations with PRK and LASIK. J Refract Surg 2009; 25: 273-276. 